\title{
Ligações em estruturas de concreto pré-moldado: pesquisas $\in$ transferências ao setor produtivo
}

\author{
MOUNIR KHALIL EL DEBS - Professor SênIOR \\ Departamento de Engenharia de Estruturas da Escola \\ de Engenharia de São Carlos da Universidade de São Paulo
}

\begin{abstract}
RESUMO
O OBJETIVO DESTE ARTIGO É APRESENTAR OS PRINCIPAIS RESULTADOS DE PESQUISAS DIRETAMENTE RELACIONADAS ÀS LIGAÇÕES DE ESTRUTURAS DE CONCRETO PRÉ-MOLDADO, DESENVOLVIDAS SOB A COORDENAÇÃO DO AUTOR, E AS TRANSFERÊNCIAS DOS RESULTADOS AO SETOR PRODUTIVO. NESSAS PESQUISAS SÃO TRATADOS DOIS TIPOS DE LIGAÇÕES: LIGAÇÃO PILAR X FUNDAÇÃO POR MEIO DE CÁLICE E LIGAÇÃO VIGA-PILAR. NO CASO DA LIGAÇÃO

POR CÁLICE DE FUNDAÇÃO SÃO APRESENTADOS MODELOS E RECOMENDAÇÕES PARA PROJETOS PARA CÁLICE E PILAR COM INTERFACES LISAS E RUGOSAS E COM INTERFACES COM CHAVES DE CISALHAMENTO. O CASO DE LIGAÇÃO VIGA $X$ PILAR, PARA ESTRUTURA DE EDIFÍCIO DE MÚLTIPLOS PAVIMENTOS, INCLUI O ESTUDO DE ALMOFADA DE ARGAMASSA MODIFICADA E CONSIDERAÇÃO DO COMPORTAMENTO SEMIRRÍGIDO.
\end{abstract}

Palavras-chave: concreto pré-moldado, ligações, pesquisas, recomendações para o projeto, transferência para o setor produtivo.

\section{INTRODUÇÃO}

[ m geral, as ligações são - as partes mais importantes no projeto das estruturas de concreto pré-moldado. Elas são de fundamental importância, tanto no que se refere à sua produção como para o comportamento da estrutura montada.

Portanto, as pesquisas sobre ligações são fundamentais para o desenvolvimento do concreto pré-moldado, justificando a atenção de pesquisadores envolvidos com o assunto.

As pesquisas relacionadas com concreto pré-moldado sob a coordenação do autor iniciaram, de forma sistemática, na década de 90, no
Departamento de Engenharia de Estruturas da Escola de Engenharia de São Carlos da Universidade de São Paulo. Grande parte das pesquisas desenvolvidas eram direcionadas às ligações, que ganharam impulso com projeto temático de pesquisa financiado pela FAPESP - Fundação de Amparo à Pesquisa do Estado de São Paulo, desenvolvido entre 2005 e 2010.

A transferência dos resultados para o setor produtivo foi sempre uma meta. Neste sentido, merece destacar os três eventos intitulados "Encontro Nacional Pesquisa-Projeto-Produção em Concreto pré-moldado", realizados em 2005, 2009 e 2013, na Escola de Engenharia de São Carlos da USP.

\section{LIGAÇÃO PILAR X FUNDAÇÃO POR MEIO DE CÁLICE}

\section{I Considerações iniciais}

Uma das formas mais comuns de fazer a ligação de pilares pré-moldados com a fundação é mediante cálice, conforme pode ser visto em El Debs (2017).

Normalmente, os cálices de fundação eram projetados no Brasil com as indicações e modelo apresentados em Leonhardt e Monnig (1978), considerando duas situações parainterfaces do pilar pré-moldado e as paredes internas do cálice: lisas ou rugosas. Entretanto, as interfaces denominadas rugosas eram na realidade interfaces com chaves de 
cisalhamento. Essas indicações eram adotadas nas versões antigas da atual NBR 9062:2017 Projeto e execução de estruturas de concreto pré-moldado (ABNT, 2017).

Embora a ligação pilar $x$ fundação por meio de cálice seja bastante difundida nas estruturas de concreto pré-moldado, havia dúvidas sobre o seu comportamento e quanto ao conservadorismo das indicações do modelo existente. Além disso, havia uma escassez de resultados experimentais. Em função do exposto, foi proposto um estudo sobre o assunto, em meados de 1999, envolvendo parte experimental e parte numérica, que posteriormente, gerou outros estudos.

A superfície interna do cálice e a superfície da base do pilar no trecho de embutimento tem um importante papel no comportamento estrutural do cálice. Em função disto, faz-se aqui uma divisão em: a) cálices de interfaces lisas e rugosas e b) cálices de interfaces com chaves de cisalhamento.

\subsection{Ligação com interfaces lisas $\epsilon$ rugosas}

Com base no modelo apresentado em Leonhardt e Monnig (1978), em outras indicações da literatura e nas pesquisas realizadas, o modelo mostrado na Figura 1 foi proposto para representar a transferência dos esforços para o caso de grandes excentricidades.

Com base nos resultados experimentais e numéricos, são propostos os valores de $e_{n b}=h / 4$ e $y=y^{\prime}=I_{e m b} / 10$. Assim, obtém-se a expressão 1 da resultante $\mathrm{H}_{\text {sfd, }}$ em função do coeficiente de atrito.

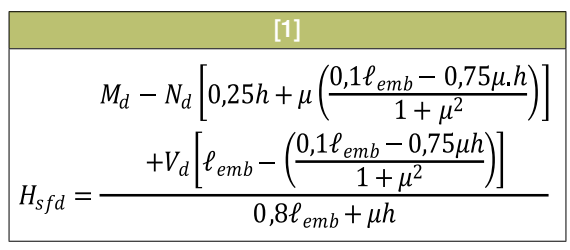

Um ponto não bem definido nas indicações em Leonhardt e Monnig (1978) era o comportamento da parede frontal, correspondente a face frontal do cálice (Figura 1). Usualmente, considerava-se que essa parede estaria sujeita apenas à flexão produzida pelas pressões sobre ela. Observou-se, no entanto, que ocorre uma flexo-tração do colarinho na parte frontal do cálice, em que $85 \%$ da tensão na armadura seriam provenientes da tração simples e $15 \%$ da flexão. No entanto, para projetos, pode-se considerar apenas a tração, pois a diferença na área necessária das armaduras é pequena.

Os resultados indicam que a resultante das pressões da parede frontal é transferida para a fundação basicamente por meio das paredes Iongitudinais. Estas paredes trabaIham como consolos submetidos à força indireta, o que torna necessária uma armadura vertical no canto da parte posterior do cálice, confirmando o comportamento apresentado em Leonhardt e Monnig (1978).

\subsection{Ligação com interfaces com chaves de cisalhamento}

Neste caso, os resultados indicaram uma significativa diferença com o modelo apresentado em Leonhardt e Monnig (1978). Assim, foi

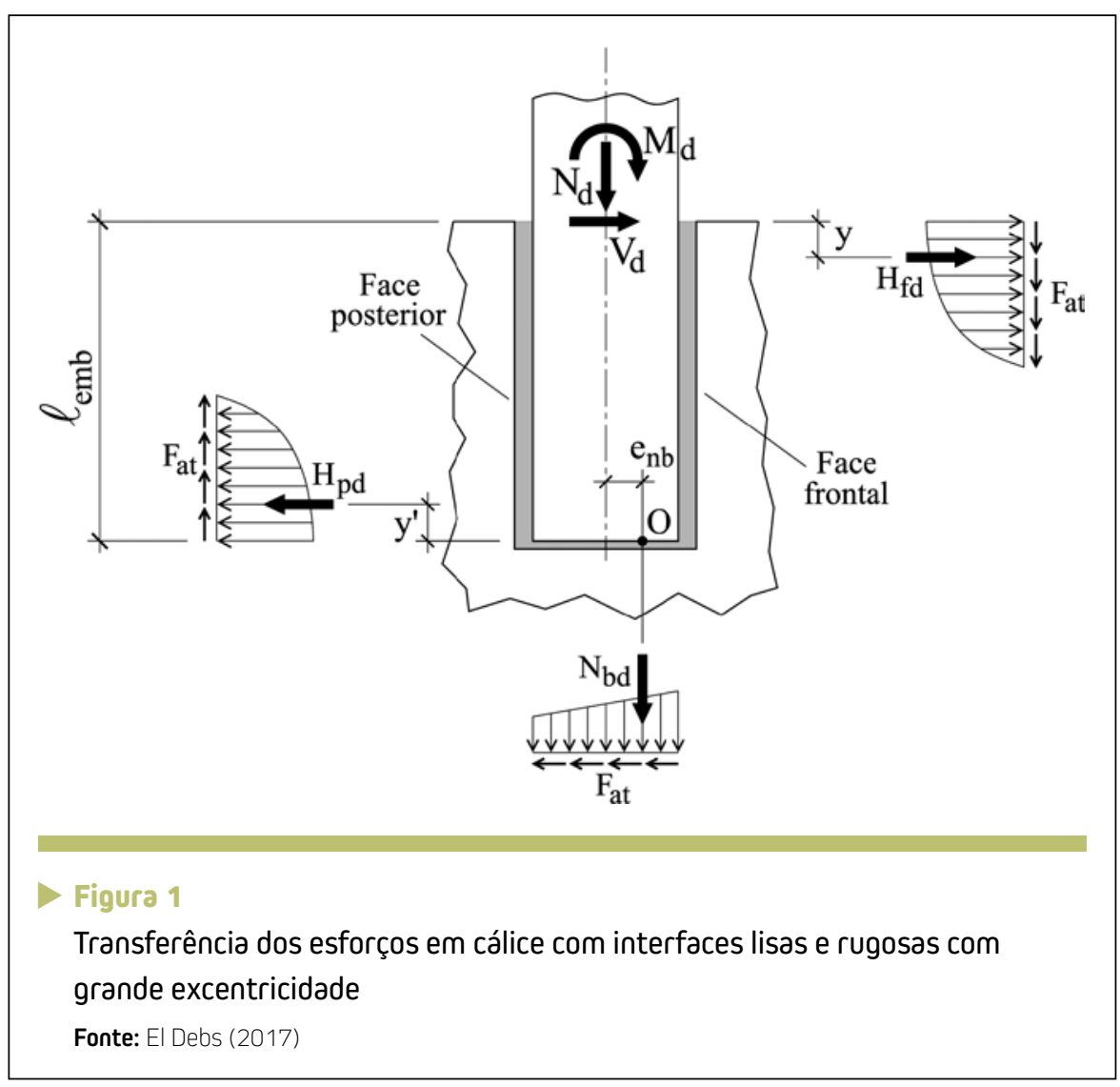




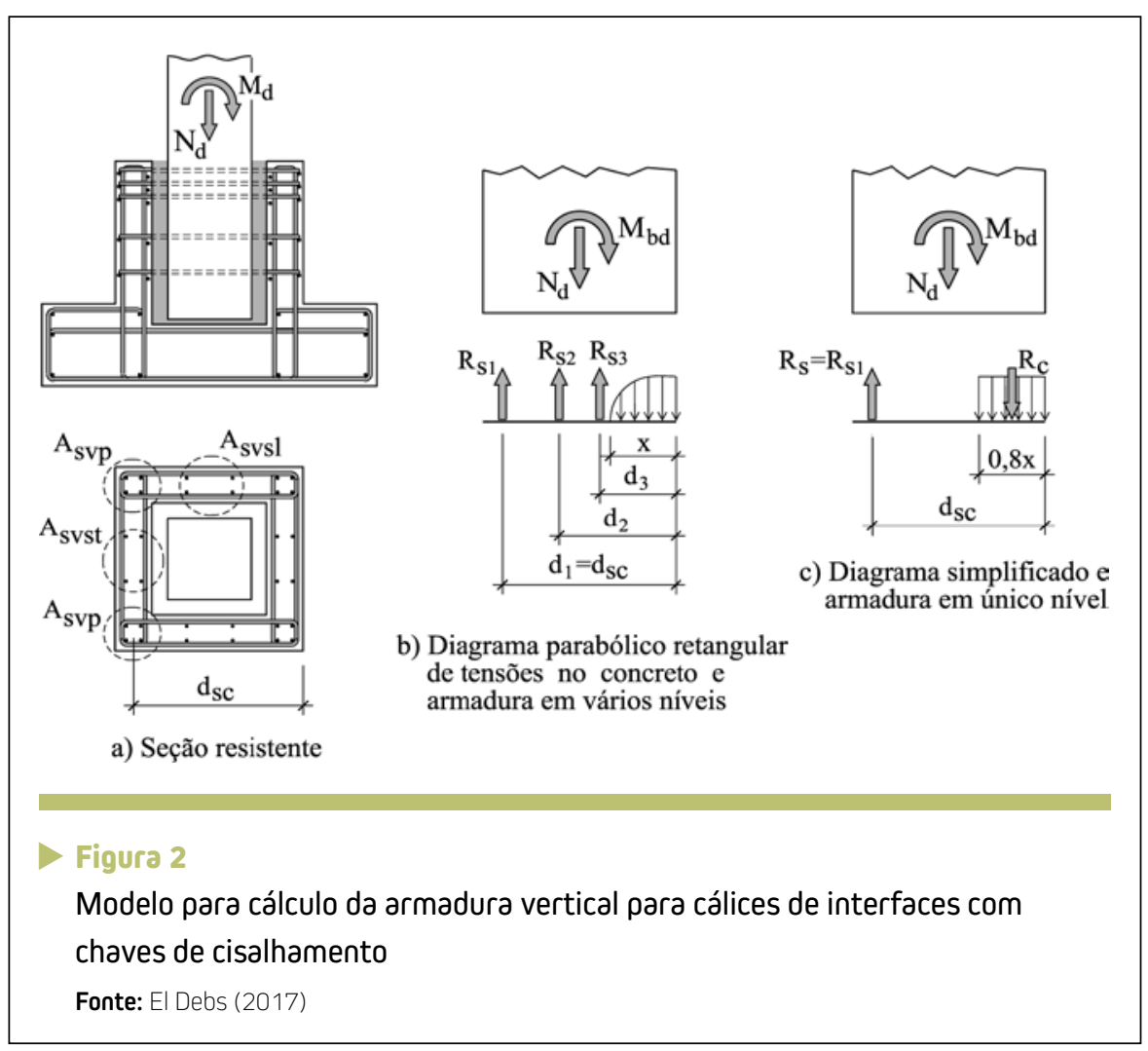

proposto um novo modelo descrito a seguir.

Como a transferência dos esforços do pilar para as paredes internas do cálice é feita por meio de bielas, ela se desenvolve praticamente em toda a altura das paredes frontal e posterior, bem como pelas paredes longitudinais. A armadura vertical é calculada conforme o modelo da Figura 2.

As bielas que fazem a transferência dos esforços do pilar para parede interna do cálice produzem pressões horizontais. Com base nos ensaios de cálices com colarinho, notou-se que a inclinação das bielas não é constante e é menos inclinada em relação à vertical na parte tracionada do pilar do que na parte comprimida. Além disso, as pressões na parte posterior do cálice tendem a se concentrar na parte supe- rior, ao passo que, na parte frontal do cálice, elas tendem a atuar ao longo de toda a parede. A Figura 3 mostra o modelo indicado para o cálculo.
Fazendo ajuste aos resultados experimentais de medidas de deformações na armadura, são sugeridos os seguintes valores para a inclinação média das bielas, em relação ao plano horizontal: a) para parede frontal $60^{\circ}$ e b) para a parede posterior $35^{\circ}$. Substituindo esses valores, considerando $d_{c}=h_{\text {ext }}-h_{c}$ e adotando $z_{c}=0,9 d_{c}$, são deduzidas as as expressões 2 e 3 para as parcelas das resultantes, no trecho de $\mathrm{I}_{\text {emb }} / 3$ contado a partir do topo do cálice:

\begin{tabular}{|c|}
\hline$H_{f d}=\frac{\left[M_{d}+V_{d} l_{e m b}+N_{d}\left(0,5 \cdot d_{c}\right)\right]}{2,60 d_{c}}$ \\
\hline$H_{p d}=\frac{\left[M_{d}+V_{d} l_{e m b}-N_{d} \cdot\left(0,4 d_{c}\right)\right]}{0,63 d_{c}}$ \\
\hline
\end{tabular}

Assim como no caso de interfaces lisas e rugosas, as pressões horizontais tendem a concentrar nos cantos, produzindo flexo-tração nas paredes frontal e posterior.

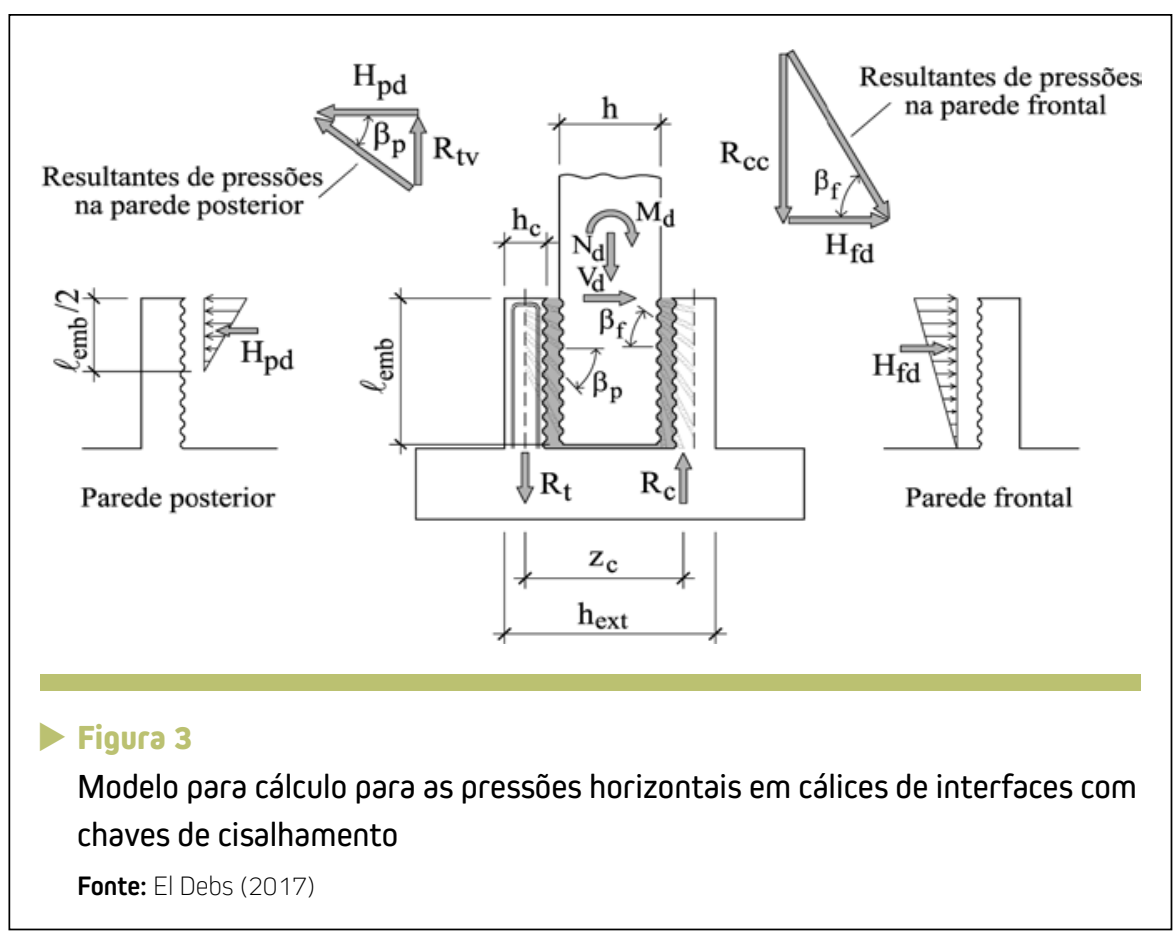




\section{LIGAÇÃO VIGA X PILAR}

\section{I Considerações iniciais}

As pesquisas relacionadas às ligações viga-pilar se justificam por ser a principal ligação das estruturas de esqueleto, tanto pelo seu papel no comportamento da estrutura como pela sua quantidade nas estruturas típicas.

As ligações viga-pilar são normalmente projetadas considerando que elas se comportam como articuladas ou perfeitamente rígidas. No entanto, elas podem apresentar um comportamento intermediário, nesse caso denominadas de ligações semirrígidas.

Neste artigo é apresentada uma síntese das pesquisas focando as ligações viga $\times$ pilar para edifícios de múltiplos pavimentos. Essas pesquisas envolveram o emprego de um novo tipo de almofadas de apoio para as vigas, as almofadas de argamassa modificada. Embora essas almofadas não sejam obrigatoriamente usadas nas ligações estudadas e possam ser usadas em outros tipos de ligações, elas têm uma relação próxima com a ligação viga- pilar pesquisada, o que justifica serem aqui tratadas.

Merece salientar que o enfoque das pesquisas sobre as ligações semirrígidas aqui tratadas é diferente daquele da NBR 9062:2017. Enquanto o enfoque da norma é a análise da estabilidade global com a rigidez apenas aos momentos fletores negativos, as pesquisas realizadas tiveram o foco de propiciar a consideração de uma rigidez às ligações usualmente tratadas como articuladas, para possibilitar, com peque- nas mudanças, aumentar a altura viável de edifícios com ligações articuladas.

\subsection{Almofadas de argamassa modificada}

A transferência de tensões de compressão nas ligações de concreto pré-moldado é geralmente feita por contato direto ou intercalando uma camada entre os componentes pré-moldados. O uso de contato direto entre os componentes é bastante limitado devido às concentrações de tensão que reduzem a eficiência da transferência. A camada entre os componentes pode ser feita usando uma almofada ou pelo preenchimento com graute ou concreto.

No caso de apoio de elementos fletidos, a transferência de tensões de compressão é, geralmente, feita com almofada de elastômero. A almofada de elastômero permite acomodar as imperfeições na superfície de contato e permite, com poucas restrições, a rotação e a translação em relação ao eixo dos elementos apoiados. A translação horizontal permite o alívio de tensões introduzidas pela variação do comprimento dos elementos horizontais apoiados. A última característica representa uma grande vantagem desse tipo de material, especialmente quando as variações de comprimento introduzem altas tensões.

De acordo com o boletim 43 da fib (fib 2008), outros materiais, mais macios que o concreto podem ser adequados para apoiar elementos de flexão, como feltro, chapas duras de madeira, plásticos, chumbo. A Almofada de Argamassa Modificada (AAM) proposta é mais macia do que o concreto, porém mais rígida do que o elastômero, dentro da mesma ideia dos materiais da almofada citados no boletim 43 da fib (fib 2008).

Comparada com as almofadas de elastômero, as AAMs acomodariam imperfeições com menos eficiência, não permitiriam deslocamentos horizontais e a capacidade de rotação é muito mais limitada. Portanto, os efeitos das variações de comprimento precisam ser considerados com mais cuidado. Por outro lado, por serem muito mais rígidas que as almofadas de elastômero, resultam em ligações mais rígidas e, portanto, estruturas menos deformáveis. Outras características favoráveis se devem ao material ser base de cimento. Dessa forma, em princípio, essas almofadas teriam a mesma durabilidade do concreto e poderiam ser incorporadas nos componentes pré-moldados, além de terem maior resistência ao fogo.

O ponto de partida foi desenvolver um material à base de cimento com características de grande deformabilidade e alta tenacidade, em comparação com a argamassa comum à base de cimento. Assim, o material para as almofadas seria feito a partir de cimento Portland e argamassa de areia, incorporando os seguintes ingredientes: a) agregados leves ou um aditivo para introduzir ar na mistura, b) látex e c) fibras curtas.

Os primeiros estudos realizados datam do final da década de 90, cujos primeiros resultados publicados em periódico são de 2003 (El Debs et al, 2003). A longo desses anos, diversas pesquisas foram realizadas, sendo 4 mestrados e várias iniciações científicas. As principais variáveis estudadas estão comentadas a seguir: 


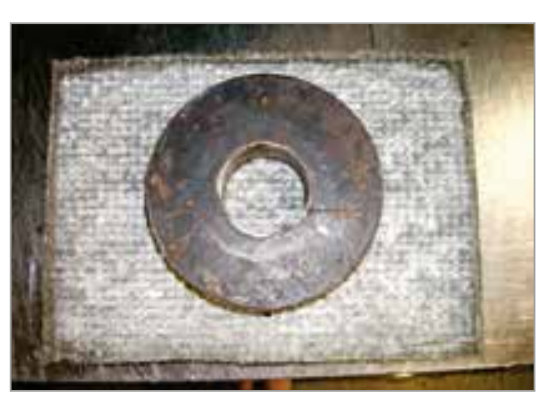

ว

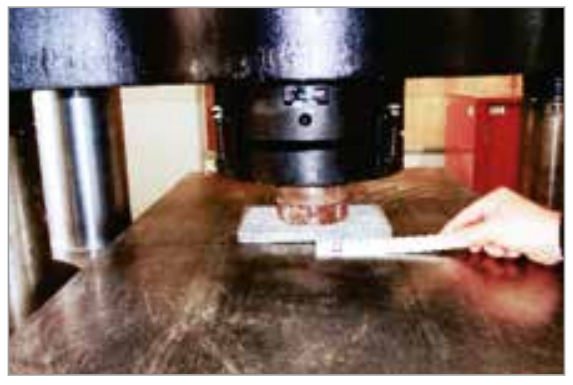

b

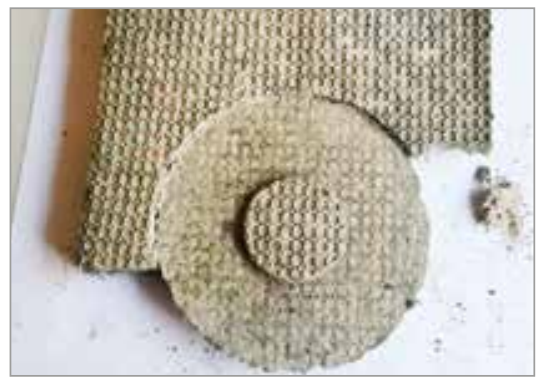

C

\section{Figura 4}

Almofada submetida à compressão, com disco metálico com orifício central

a) composição e tipos de fibras: os estudos concentraram no uso de cimento Portland de alta resistência inicial, de areia natural, de vermiculita termo-expandida de pequeno tamanho (diâmetro máximo de 2,4 $\mathrm{mm}$ ), como agregado leve, de polímero estireno-butadieno, SB 112 (látex) e de fibras de polipropileno, de PVA e de vidro;

b) ensaios nas AAM: foram realizados ensaios de compressão uniforme para determinação da deformação e da rigidez, ensaios de força concentrada para avaliar a tenacidade, ensaio cíclicos para avaliar a danificação;

c) incorporação de rugosidade: foi feito estudo para avaliar o aumento da deformabilidade mediante a incorporação de rugosidade às AAM;

d) ensaios de compressão em blocos: estes ensaios visavam à avaliação das AAM em ligações submetidas predominantemente à compressão.

A Figura 4 apresenta um teste para mostrar a maleabilidade do material, no qual a AAM foi submetida à compressão, com um disco metálico com orifício central (Figura 4a), em uma máquina universal de ensaio ( $\mathrm{Fi}$ gura 4b). A Figura 4c mostra a AAM após o ensaio, onde pode-se obser- var o afundamento pronunciado na posição do disco.

\subsection{Ligação viga x pilar para estrutura de múltiplos pavimentos}

O ponto de partida para esta pesquisa foi a ligação viga-pilar, em que as vigas se apoiam em almofadas de elastômero usualmente empregadas em edifícios de pequena altura. Esta ligação é normalmente considerada uma articulação no cálculo estrutural. Foram propostas duas modificações nessa ligação: o emprego da almofada de argamassa modificada e o pre- enchimento do espaço entre a parte superior da viga e o pilar com graute, conforme mostra a Figura 5.

As mudanças em relação à forma usual não alteram a ligação em relação à estética e tolerâncias envolvidas. Em relação à sua execução, existe um trabalho adicional em campo para preencher o espaço entre a viga e o pilar com graute.

Em relação ao comportamento estrutural, ocorre uma transmissão parcial de momento fletor, que deve ser maior para momentos negativos e menor para momentos positivos. Para a viga, a transmissão de momento fletor pela ligação produziria a redução dos

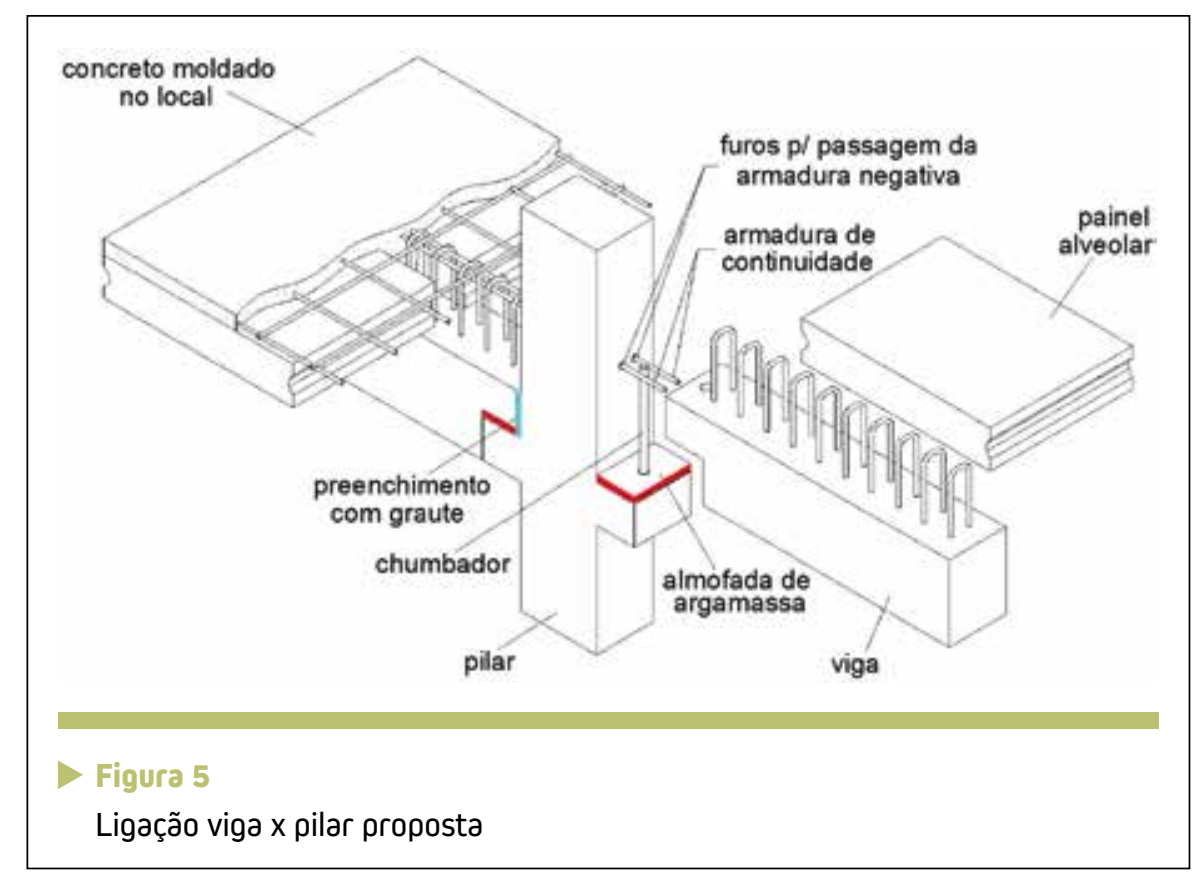


> Tabela 1 - Resultados com aumento do número de andares

\begin{tabular}{|c|c|c|c|c|c|c|c|}
\hline \multirow[b]{2}{*}{ Ligação } & \multirow[b]{2}{*}{$n^{(1)}$} & \multicolumn{3}{|c|}{ Combinação $G+Q+W$} & \multicolumn{3}{|c|}{ Combinação G + W } \\
\hline & & $\begin{array}{c}\mathrm{a} \\
(\mathrm{mm})\end{array}$ & $\gamma_{z}$ & $\begin{array}{l}\mathrm{Mb} \cdot \gamma_{z} \\
(\mathrm{kN} \cdot \mathrm{m})\end{array}$ & $\underset{(\mathrm{mm})}{\mathrm{a}}$ & $\gamma_{2}$ & $\begin{array}{l}\mathrm{Mb} \cdot \gamma_{z} \\
(\mathrm{kN} \cdot \mathrm{m})\end{array}$ \\
\hline Articulação & 2 & 29,77 & 1,19 & 44,65 & 29,77 & 1,12 & 0 \\
\hline \multirow{4}{*}{ Semirrígida } & 2 & 4,07 & 1,03 & 18,73 & 4,07 & 1,02 & 3,99 \\
\hline & 3 & 11,30 & 1,05 & 33,94 & 11,30 & 1,03 & 8,52 \\
\hline & 4 & 21,81 & 1,07 & 49,29 & 21,81 & 1,05 & 13,13 \\
\hline & 5 & 36,30 & 1,10 & 66,26 & 36,30 & 1,06 & 17,00 \\
\hline
\end{tabular}

momentos positivos no meio do vão, para as cargas verticais aplicadas após a ligação se tornarem efetivas. Já, para as ações laterais, haveria um momento fletor negativo em uma extremidade e positivo na outra extremidade. Assim, resultaria em um acréscimo dos momentos fletores negativos em uma extremidade, quando superpõe as ações verticais e laterais. No entanto, quando se tratar de edifícios com pouco número de andares, este acréscimo é pequeno. O mais importante, para tornar viável o aumento de número de andares é que a transmissão dos momentos fletores, mesmo que parcial, reduziria os momentos fletores nos pilares para as ações laterais, em comparação com o caso de articulações. A redução dos momentos nos pilares possibilitaria uma redução da seção transversal dos mesmos, ou, mantendo a seção transversal, poder-se-ia aumentar a altura da construção.

As pesquisas relacionadas com esta ligação iniciaram junto com as das almofadas de argamassa modificada, no final da década de 90. Em El Debs (2017), apresenta-se uma síntese dos trabalhos acadêmicos relacionados com o tema.
No primeiro trabalho acadêmico, foi realizado um programa experimental com dois protótipos da ligação. Baseado nesse programa experimental e outros estudos, foi proposta uma idealização do comportamento estrutural, detalhado em El Debs et al (2010) e mostrado na Figura 6.

Com o objetivo de avaliar a influência da ligação proposta, apresenta-se uma simulação numérica para estrutura típica de edifício entre 2 a 5 andares e 3 vãos, comparando a ligação semirrígida com a ligação articulada. Os detalhes podem ser vistos em El Debs et al (2010).

A Tabela 1 apresenta os principais resultados, onde se pode observar que é possível aumentar o número de andares de 2, no caso de ligação articulada, para 4, com a ligação semirrígida, pois o deslocamento no topo da estrutura é menor e o momento fletor no pé do pilar é apenas um pouco maior, o poderia ser atendido com um pequeno acréscimo na armadura. Outra importante constatação é que, passando para 5 andares, o momento positivo na ligação ainda é menor que o momento último. No entanto, neste caso o momento fletor na base do pilar é bem maior que o momento fletor da estrutura com dois andares e ligação articulada.

\section{SÍNTESE DOS RESULTADOS E TRANSFERÊNCIA PARA 0 SETOR PRODUTIVO}

Os principais resultados estão alinhavados a seguir.

Em relação aos cálices de fundação com interfaces lisas e rugosas:

a) as resultantes das pressões do pilar no cálice podem ser calculadas com equação que leva em conta o atrito e a excentricidade da reação na base do cálice; a consideração desses efeitos reduz os esforços transferidos e, consequentemente, as armaduras;

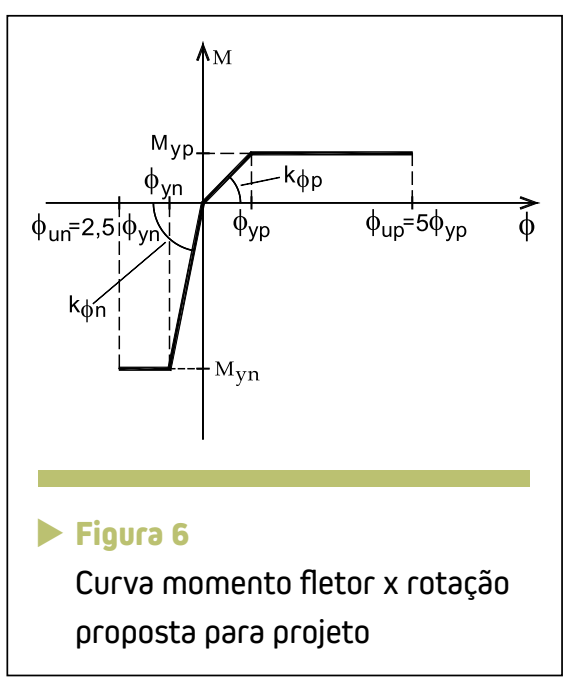




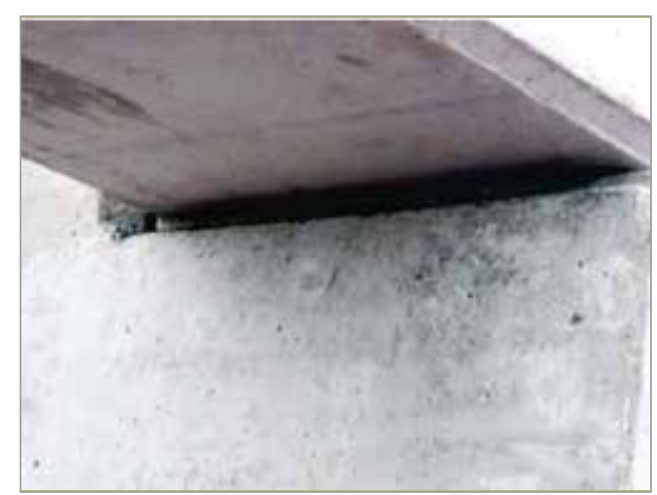

a

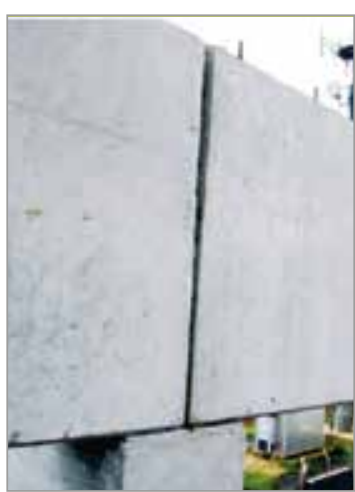

b

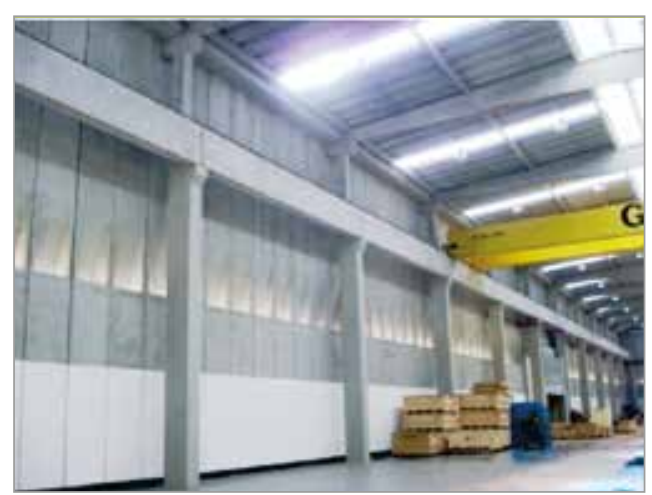

C

\section{Figura 7}

Exemplo de aplicação das almofadas de argamassa modificada

b) A parede transversal frontal é submetida à flexo-tração; como simplificação, pode-se considerar somente a força de tração; neste caso, também ocorre uma redução da armadura em relação ao modelo anteriormente utilizado de considerar apenas flexão.

Em relação aos cálices com chaves de cisalhamento:

a) foi desenvolvido um novo modelo para a transferências dos esforços;

b) o dimensionamento da armadura vertical feito com a teoria da flexão resulta em significativa redução da mesma; c) as armaduras horizontais podem ser calculadas com modelo de transferência de esforços com bielas, que produzem maiores esforços na parte superior, tanto na parede transversal frontal como na parede transversal posterior; neste caso, ocorre um aumento da quantidade de armadura.

Em relação as almofadas de argamassa modificada:

a) as dosagens recomendadas para o material das almofadas têm relação cimento/agregado de 0,3, relação cimento/água de 0,4, porcentagem de vermiculita, em relação à mas- sa total de agregados, de 5 a 15\%, taxa volumétrica de fibras de $2 \%$, ou mais, e quantidade de látex de 20 a 30\% da massa de cimento;

b) os valores representativos do material com estas dosagens seriam: resistência à compressão média de 20 MPa a 45 MPa e módulo de elasticidade de 10 GPa a 15 GPa;

C) as espessuras recomendas para AAM são de 10 mm a 20 mm, com emprego de rugosidade dos dois lados; a rigidez das almofadas, que é a relação da tensão aplicada com a sua deformação, seria da ordem de $300 \mathrm{MPa}$ a $500 \mathrm{MPa}$.

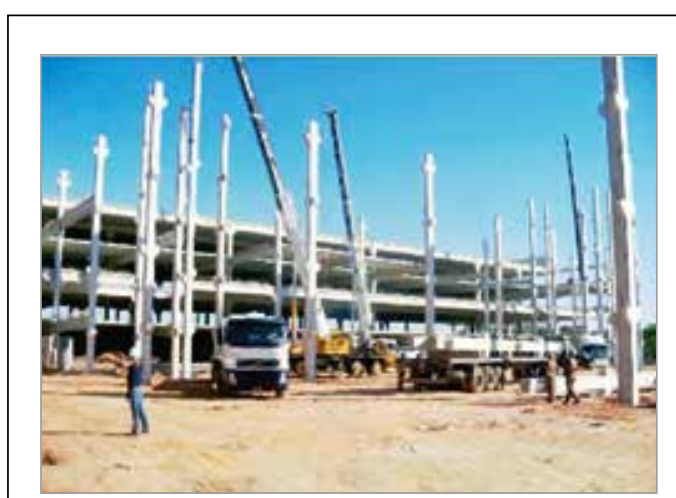

a - BR Parking

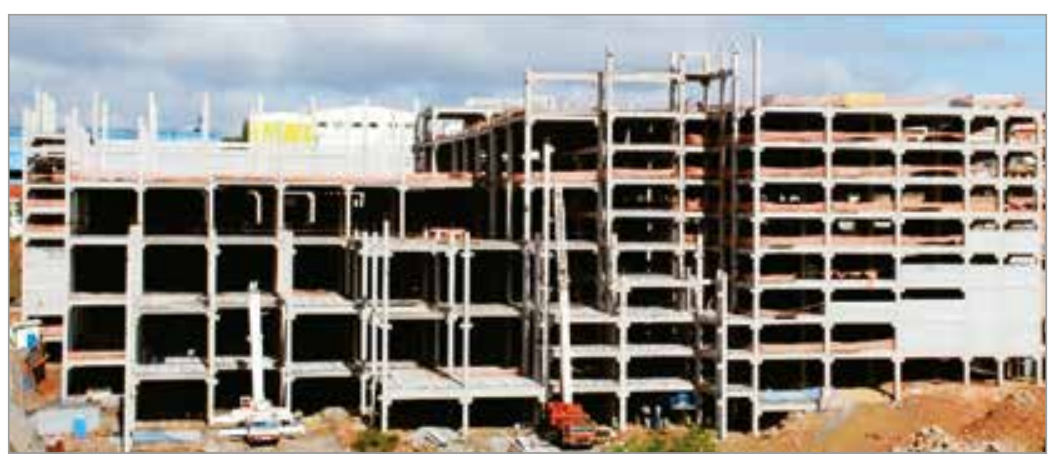

b - Plaza Shopping Carapicuiba

Figura 8

Exemplos de aplicação de ligação semirrígidas

Fonte: El Debs et al (2015) 
Em relação à ligação viga-pilar desenvolvida:

a) é proposto um comportamento da bilinear para a relação momento fletor vs rotação, tanto para momentos negativos como para momentos positivos;

b) para uma situação representativa, a ligação possibilita aumentar a viabilidade de altura de edifício de 2 andares para 4 andares, mantendo a estrutura com ligação articulada , com menor deslocamento no topo do pilar, mas às custas de um pequeno aumento do momento fletor no pilar. Apresenta-se a seguir a transferência dos resultados para o setor produtivo. Em relação aos cálices de fundação:

a) os resultados das pesquisas desenvolvidas foram, na sua maior parte, incorporados na atual NBR 9062:2017, em substituição às indicações de Leonhardt e Monnig (1978), que constava nas edições anteriores dessa norma.

Em relação às almofadas de argamassa modificada:

a) a empresa Marka Soluções Pré-fabricadas tem usado regularmente as almofadas: a Figura 7 mostra uma aplicação feita em 2007.

Em relação a ligação viga-pilar: a) a ligação e as indicações para o projeto têm sido utilizadas no setor produtivo: a Figura 8 mostra duas obras projetadas com base nos resultados.

\section{AGRADECIMENTOS}

À CAPES e ao CNPq pelas bolsas concedidas aos alunos de pós-graduação envolvidos. À FAPESP, pelo apoio através do projeto temático "Nucleação e incremento da pesquisa, inovação e difusão em concreto pré-moldado e estruturas mistas para a Modernização da Construção Civil" (proc. 05/53141-4).

\section{> REFERÊNCIAS BIBLIOGRÁFICAS}

[1] EL DEBS, MK Concreto pré-moldado: fundamentos e aplicações. 2.ed. São Paulo: Oficina de Textos, 2017, 456p.

[2] LEONHARDT, F; MONNIG, E Construções de concreto: princípios básicos sobre armação de estruturas de concreto armado. Rio de Janeiro: Interciência. v.3, 1978.

[3] ASSOCIAÇÃO BRASILEIRA DE NORMAS TÉCNICA. NBR 9062:2017 Projeto e execução de estruturas de concreto pré-moldado. Rio de Janeiro: ASSOCIAÇÃO BRASILEIRA DE NORMAS TÉCNICA, 2017.

[4] FÉDÉRATION INTERNATIONALE DU BÉTON Bulletin 43 Structural connections for precast concrete buildings. Fédération internationale du béton (fib), Lausanne, 2008

[5] EL DEBS, MK, BARBOZA, ASR; MIOTTO, AMM Development of material to be used as bearing pad in precast concrete connections. Structural Concrete, v.4, n. 4 , pp. 185-193. 2003.

[6] EL DEBS, MK, MIOTTO, AM; EL DEBS, ALHC Analysis of a semi-rigid connection for precast concrete. Proceedings of the Institution of Civil Engineers: Structures and Buildings, v.163, n.1, pp. 41-51. 2010.

[7] EL DEBS, M K.; MARIN, M C; EL DEBS, ALH C Design parameters for multy-storey precast concrete structures with semi-rigid connection. In: fib SYMPOSIUM, 1. 2015, Copenhagen. Proceedings... Copenhagen: fib, 2015. p. 1-11.

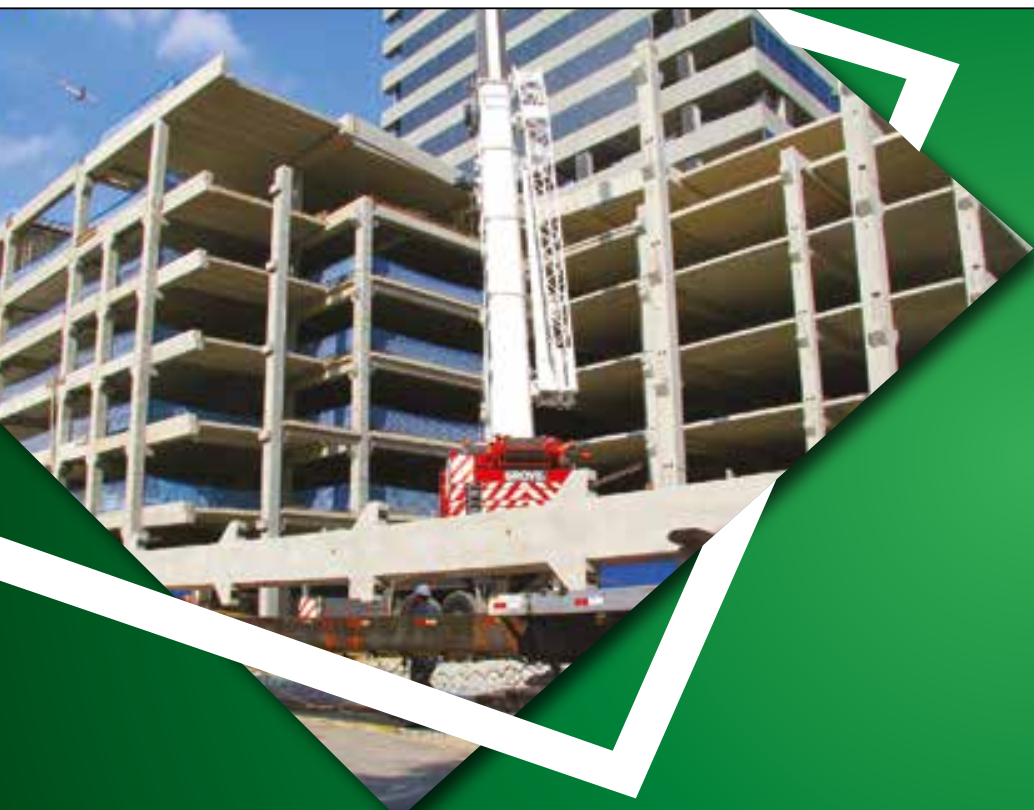

A Abcic, representando as soluções em estruturas, fachadas e fundações pré-fabricadas de concreto, parabeniza o IBRACON pela 100ª edição da Revista Concreto \& Construções! Importante veículo de disseminação da cultura e da engenharia de concreto no Brasil. 